\title{
Assessment of Body Composition in Dialysis Patients by Arm Bioimpedance Compared to $\mathrm{MRI}$ and ${ }^{40} \mathrm{~K}$ Measurements
}

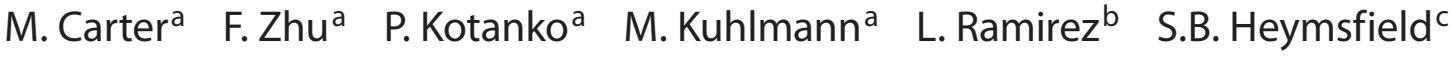 \\ G. Handelman ${ }^{a}$ N.W. Levin ${ }^{a}$ \\ ${ }^{a}$ Renal Research Institute, ${ }^{b}$ Brookhaven National Laboratory, and 'St. Luke's-Roosevelt Hospital Center, \\ New York, N.Y., USA
}

\section{Key Words}

Segmental bioimpedance $\cdot$ Magnetic resonance imaging .

Skeletal muscle mass $\cdot$ Subcutaneous adipose tissue

\begin{abstract}
This study used multi-frequency bioimpedance spectroscopy (BIS) of the arm and whole body to estimate muscle mass (MM) and subcutaneous adipose tissue (SAT) in 31 hemodialysis (HD) patients comparing these results with magnetic resonance imaging (MRI) and body potassium $\left({ }^{40} \mathrm{~K}\right)$ as gold standards. Total body and arm MM ( $\left.\mathrm{MM}_{\mathrm{MRI}}\right)$ and SAT (SAT $\left.\mathrm{MRI}\right)$ were measured by MRI. All measurements were made before dialysis treatment. Regression models with the arm (aBIS) and whole body (wBIS) resistances were established. Correlations between gold standards and the BIS model were high for the arm SAT $\left(r^{2}=0.93\right.$, standard error of estimate $(\mathrm{SEE})=3.6 \mathrm{~kg})$, and whole body SAT $\left(r^{2}=0.92\right.$, SEE $\left.=3.5 \mathrm{~kg}\right)$, and for arm MM ( $\left.r^{2}=0.84, \mathrm{SEE}=2.28 \mathrm{~kg}\right)$ and whole body MM $\left(r^{2}=0.86\right.$, SEE $\left.=2.28 \mathrm{~kg}\right)$. Total body MM and SAT can be accurately predicted by arm BIS models with advantages of convenience and portability, and it should be useful to assess nutritional status in HD patients.
\end{abstract}

Copyright $\odot 2009$ S. Karger AG, Basel
(C) 2009 S. Karger AG, Basel

0253-5068/09/0274-0330\$26.00/0

Fax +41613061234 E-Mail karger@karger.ch www.karger.com

\section{Introduction}

The nutritional status of hemodialysis (HD) patients affects their quality of life and survival [1-5]. Change in skeletal muscle mass (MM) is an important index of nutritional status [6-8]. Gold standard techniques, such as magnetic resonance imaging (MRI), dual-energy X-ray absorptiometry and body potassium $\left({ }^{40} \mathrm{~K}\right)$, are available to estimate body composition. Total body potassium (TBK) has been used to indicate body cell mass $[9,10]$. A recent study described a technique for measuring partial body potassium in the arm $\left(\mathrm{PBK}_{\mathrm{Arm}}\right)$ and correlated this to TBK [11]. However, these techniques are impractical for use in dialysis patients because of cost and inconvenience.

Bioimpedance spectroscopy (BIS) is a noninvasive and inexpensive method which has been widely used in the study of body fluid and body composition [12-16]. The current standard method uses a wrist to ankle, the so called whole body BIS (wBIS) approach, to measure elements of body composition. The advantage of wBIS is simplicity of operation and high reproducibility. However, the ratio of the cross-sectional area and the length of segments of the limbs and the trunk are so disparate that application of a cylindrical model to obtain an accurate assessment of body composition is unsatisfactory. 
Segmental bioimpedance measurement (SBIS) has been proposed to overcome this weakness of wBIS $[17,18]$. Recently, the sum of SBIS has been developed to measure the arm, trunk and leg fluid volumes and skeletal MM [13, 19]. The current question is whether we can apply the measurement of arm bioimpedance to predict total body muscle and fat for clinical applications. It is possible to estimate total body composition, muscle or fat mass, by using one of the limbs such as the arm or leg because the human body is highly symmetrical in its components so that total body composition, muscle and fat mass, can be derived [20, 21]. Measurements made using the arm would be more convenient than the leg or whole body for dialysis patients if accuracy was similar. The aims of this study were to establish models in dialysis patients using arm and whole body BIS and to evaluate the models by comparing with MRI and ${ }^{40} \mathrm{~K}$.

\section{Subjects and Methods}

\section{Subjects}

Thirty-one stable African-American HD patients, 17 male and 14 female, weight $55.7 \pm 4.5 \mathrm{~kg}$, BMI $27.6 \pm 5.5$, were studied before a HD treatment. The study protocol was approved by the Institutional Review Board of Beth Israel Medical Center. All patients gave informed consent to the study.

\section{Measurements}

MRI

MRI was performed using a 1.5 Tesla scanner (6X Horizon; General Electric, Milwaukee, Wisc., USA). All MRI scans were segmented into components using image analysis software (Tomovision, Montreal, Que., Canada). The MRI protocol included the acquisition of 40 axial images of $10-\mathrm{mm}$ thickness at $40-\mathrm{mm}$ intervals [22]. Skeletal muscle mass $\left(\mathrm{MM}_{\mathrm{MRI}}\right)$ and subcutaneous adipose tissue (SAT) were calculated with MRI data [22, 23].

${ }^{40} \mathrm{~K}$

A natural radioisotope of potassium, ${ }^{40} \mathrm{~K}$, was used to estimate TBK using a whole body counter $[19,22]$, and $\mathrm{PBK}_{\text {Arm }}[11]$ using the nondialysis access arm. TBK and $\mathrm{PBK}_{\mathrm{Arm}}$ were measured in the Body Composition Laboratory (St. Luke's-Roosevelt Hospital, New York, N.Y., USA) [22]. It should be noted that the length of arm inserted into the ${ }^{40} \mathrm{~K}$ counter was not exactly the same length of the arm BIS measurement due to the limitation of geometrical size in the ${ }^{40} \mathrm{~K}$ counter. If a patient's arm was longer than the size of the ${ }^{40} \mathrm{~K}$ counter, the whole arm could not be measured.

\section{SBIS}

Measurement of BIS in the arm and whole body were performed at the same time using a multi-frequency bioimpedance spectroscopic device (Xitron 4200; Xitron Technologies Inc., San Diego, Calif., USA). For the arm measurement, four electrodes, two for injecting current (on the dorsum of the hand and the acromion) and two for measuring voltage (on the dorsum of wrist and greater tubercle), were placed on the nondialysis side. The whole body measurement was performed with the standard wrist to ankle technique [24]. The range of injecting current frequencies was from $5 \mathrm{kHz}$ to $1 \mathrm{MHz}$. Extracellular (Re) and intracellular resistance $(\mathrm{Ri})$ were obtained in the arm and wrist to ankle using the Xitron program based on the Cole-Cole model [24]. Extracellular (ECVa) and intracellular volumes (ICVa) in the arm were calculated according to the arm Re and $\mathrm{Ri}$ [19]. Total arm fluid volume $\left(\mathrm{TAV}_{\mathrm{BIS}}\right)$, calculated by SBIS, was defined by $\mathrm{TAV}_{\mathrm{BIS}}=\mathrm{ECVa}+\mathrm{ICVa}$.

Anthropometric Measurements

The length of the arm was defined as the distance between two measurement electrodes. The maximal and minimal circumferences of the arm were measured with $0.1 \mathrm{~cm}$ accuracy using a soft tape. Body height and weight were measured using an electronic scale and a wall-mounted stadiometer.

Arm Volume Calculation

Total geometric volume $\left(\mathrm{V}_{\mathrm{G}}\right)$ in the arm was calculated using the length and cross-sectional area of arm by anthropometric measurements as follows:

$$
V_{G}=\frac{\left(C_{\min }+C_{\max }\right)^{2}}{16 \pi} \times L
$$

where $\mathrm{C}_{\min }$ and $\mathrm{C}_{\max }$ are the minimal and maximal circumferences, and $L$ is the length of the arm.

Fat-free mass (FFM) in the arm was calculated with the equation:

$$
\mathrm{FFM}_{\text {Arm }}=\mathrm{TAV}_{\mathrm{BIS}} / \mathrm{k} \text {, }
$$

where $\mathrm{k}=0.75$ and 0.80 are assuming constants for male and female patients, respectively, as described previously [19].

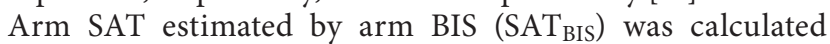
with:

$$
\mathrm{SAT}_{\mathrm{BIS}}=\left|\mathrm{V}_{\mathrm{G}}-\mathrm{FFM}_{\mathrm{Arm}}\right| .
$$

\section{Data Analysis}

Data are presented as mean $\pm \mathrm{SD}$. Linear regression analysis was performed to study the correlation between the values measured by the BIS, MRI and ${ }^{40} \mathrm{~K}$. Regression models were fitted with the resistances and volumes in the arm and whole body BIS plus the body mass, height and length of the arm using the program SYSTAT (Systat Software Inc., Chicago, Ill., USA). Bland-Altman analysis was used to identify the agreement between the values by gold standard and by the models. Comparison of differences in the values of measurements between groups was performed by $t$ test using GraphPad Prism 4 (Graphpad Inc., San Diego, Calif., USA). A significant difference was considered to be $\mathrm{p}<0.05$.

\section{Results}

All measurement data are summarized by gender in table 1 . Males have significantly higher arm $\mathrm{TAV}_{\mathrm{BIS}}$, $\mathrm{ECV}_{\mathrm{a}}, \mathrm{ICV}_{\mathrm{a}}, \mathrm{FFM}_{\mathrm{Arm}}, \mathrm{V}_{\mathrm{G}}$ and body height than females but insignificant differences in body mass. Table 2 shows 

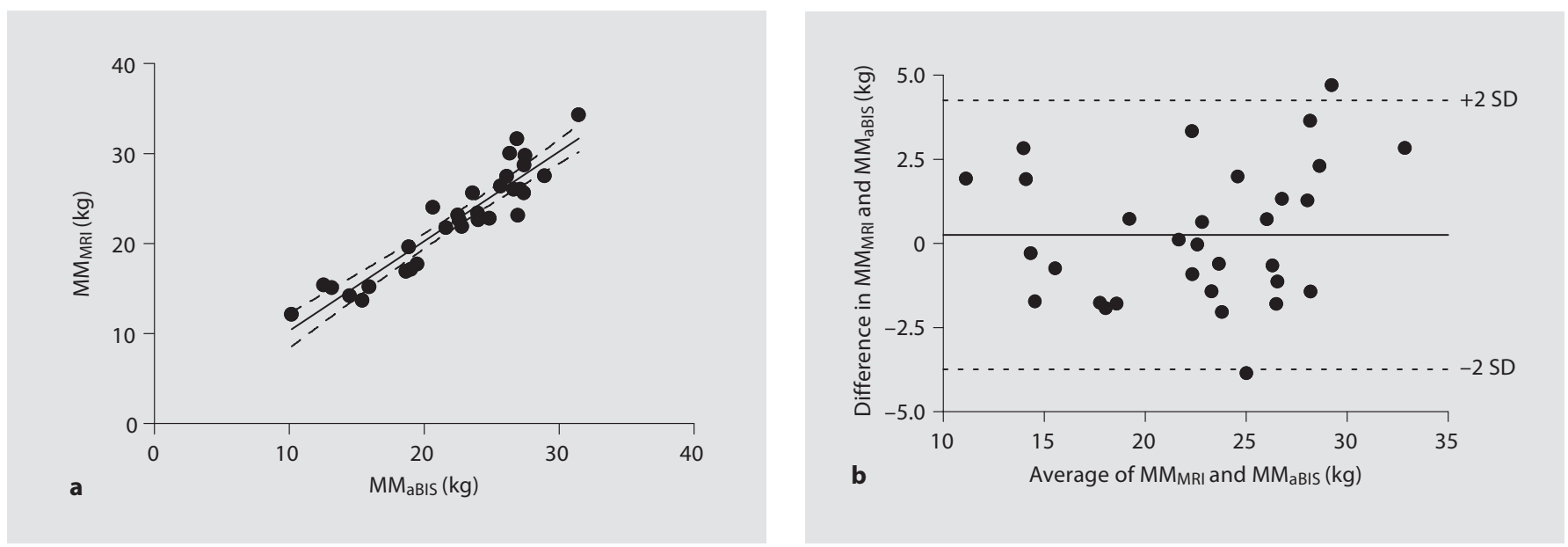

Fig. 1. a Correlation $\left(r^{2}=0.842, \mathrm{SEE}=2.28\right)$ between whole body $\mathrm{MM}_{\mathrm{MRI}}$ and $\mathrm{arm} \mathrm{MM}_{\mathrm{aBIS}}$ by the model (equation 4). b Result of the Bland-Altman analysis (bias -0.257 with the range from -3.74 to 4.25 ).

Table 1. Summary of measurements

\begin{tabular}{lccc}
\hline & Females & Males & $\mathrm{p}$ \\
\hline Number of patients & 14 & 17 & \\
Height, m & $1.6 \pm 0.07$ & $1.74 \pm 0.06$ & $<0.001$ \\
Body mass, kg & $73 \pm 19.3$ & $81.7 \pm 15$ & $\mathrm{~ns}$ \\
BMI & $28.3 \pm 6$ & $27.0 \pm 5$ & 0.5 \\
Arm length, cm & $51.7 \pm 3.2$ & $59.0 \pm 2.1$ & $<0.001$ \\
$\mathrm{C}_{\text {max }}, \mathrm{cm}$ & $33.8 \pm 6.5$ & $33.8 \pm 3.9$ & $\mathrm{~ns}$ \\
$\mathrm{C}_{\text {min }}, \mathrm{cm}$ & $16.2 \pm 1.4$ & $17.7 \pm 1.9$ & $<0.05$ \\
$\mathrm{C}_{\text {ave }}, \mathrm{cm}$ & $25 \pm 3.8$ & $25.8 \pm 2.1$ & 0.5 \\
ECV $_{\mathrm{a}}$, liters & $0.64 \pm 0.11$ & $1.0 \pm 0.14$ & $<0.001$ \\
ICV $_{\mathrm{a}}$, liters & $0.71 \pm 0.14$ & $1.1 \pm 0.2$ & $<0.001$ \\
TAV $_{\text {BIS }}$, liters & $1.35 \pm 0.23$ & $2.1 \pm 0.26$ & $<0.001$ \\
FFM $_{\text {Arm }}$, kg & $1.7 \pm 0.28$ & $2.8 \pm 0.34$ & $<0.001$ \\
Arm V $_{\mathrm{G}}$, liters & $2.6 \pm 0.7$ & $3.1 \pm 0.5$ & $<0.05$ \\
\hline
\end{tabular}

the comparison of gold standard methods with the estimation by the BIS models in the arm and whole body. The arm, TBK and $M_{M R I}$ were significantly higher, but $\mathrm{SAT}_{\mathrm{MRI}}$ was lower in the males than in the females. Measurements with both arm and whole body techniques of total body MM and SAT did not differ between gold standard and BIS estimations.

The arm BIS model for estimation of whole body MM with the model including arm length (L), Re, Ri, body mass (BM), height $(\mathrm{H})$ and age is as follows:

$$
\begin{aligned}
& M M_{M R I}=-0.018 R e-0.007 R i+0.114 H+ \\
& 0.136 B M-0.103 \text { Age }+0.359 L-12.034 .
\end{aligned}
$$

Table 2. Comparison of values of gold standard and calculations

\begin{tabular}{lccc}
\hline & Females & Males & $\mathrm{p}$ \\
\hline${\text { Arm } \mathrm{MM}_{\mathrm{MRI}}, \mathrm{kg}}$ & $1.29 \pm 0.3$ & $2.15 \pm 0.2$ & $<0.001$ \\
Arm SAT $_{\mathrm{MRI}}, \mathrm{kg}$ & $1.6 \pm 0.8$ & $1.0 \pm 0.5$ & $<0.05$ \\
Total MM $_{\mathrm{MRI}}, \mathrm{kg}$ & $18.2 \pm 4.7$ & $26.3 \pm 3.5$ & $<0.001$ \\
Total SAT $_{\mathrm{MRI}}, \mathrm{kg}$ & $27.2 \pm 12$ & $18.9 \pm 9.7$ & $<0.05$ \\
PBK $_{\text {Arm }}, \mathrm{g}$ & $4.9 \pm 0.86$ & $7.3 \pm 0.87$ & $<0.001$ \\
TBK, g $_{\text {Arm MM }}$ & $2,609 \pm 458$ & $3,571 \pm 342$ & $<0.001$ \\
Arm SAT $_{\mathrm{aBIS}}, \mathrm{kg}$ & $2.11 \pm 0.26$ & $2.1 \pm 0.25$ & $\mathrm{~ns}$ \\
Total MM $_{\mathrm{aBIS}}, \mathrm{kg}$ & $1.6 \pm 0.74$ & $1.1 \pm 0.4$ & $<0.05$ \\
Total SAT $_{\mathrm{aBIS}}, \mathrm{kg}$ & $18.34 \pm 5.1$ & $25.7 \pm 2.8$ & $<0.0001$ \\
Total MM $_{\mathrm{wBIS}}, \mathrm{kg}$ & $26.7 \pm 10$ & $19.7 \pm 10.6$ & $\mathrm{~ns}$ \\
Total SAT $_{\mathrm{wBIS}}, \mathrm{kg}$ & $18.21 \pm 5.5$ & $25.15 \pm 2.8$ & $<0.0001$ \\
& $26.4 \pm 9.9$ & $20.3 \pm 11$ & $\mathrm{~ns}$ \\
\hline
\end{tabular}

Whole body SAT was estimated by the arm BIS model by equation 5 .

$$
\begin{aligned}
& S A T_{M R I}=0.064 R e+0.008 R i-0.281 H+ \\
& 0.73 B M+0.116 \text { Age }-0.666 L+21.64
\end{aligned}
$$

The correlation $\left(\mathrm{r}^{2}=0.925\right.$, standard error of estimate $(\mathrm{SEE})=3.6)$ and agreement with Bland-Altman analysis (bias -0.205 with the range from -6.26 to 5.85 ) between gold standard and estimation with equation 5 are shown in figure 2.

The whole-body BIS model to estimate whole body $\mathrm{MM}$ is shown in equation 6 and the model to estimate SAT is shown in equation 7. 

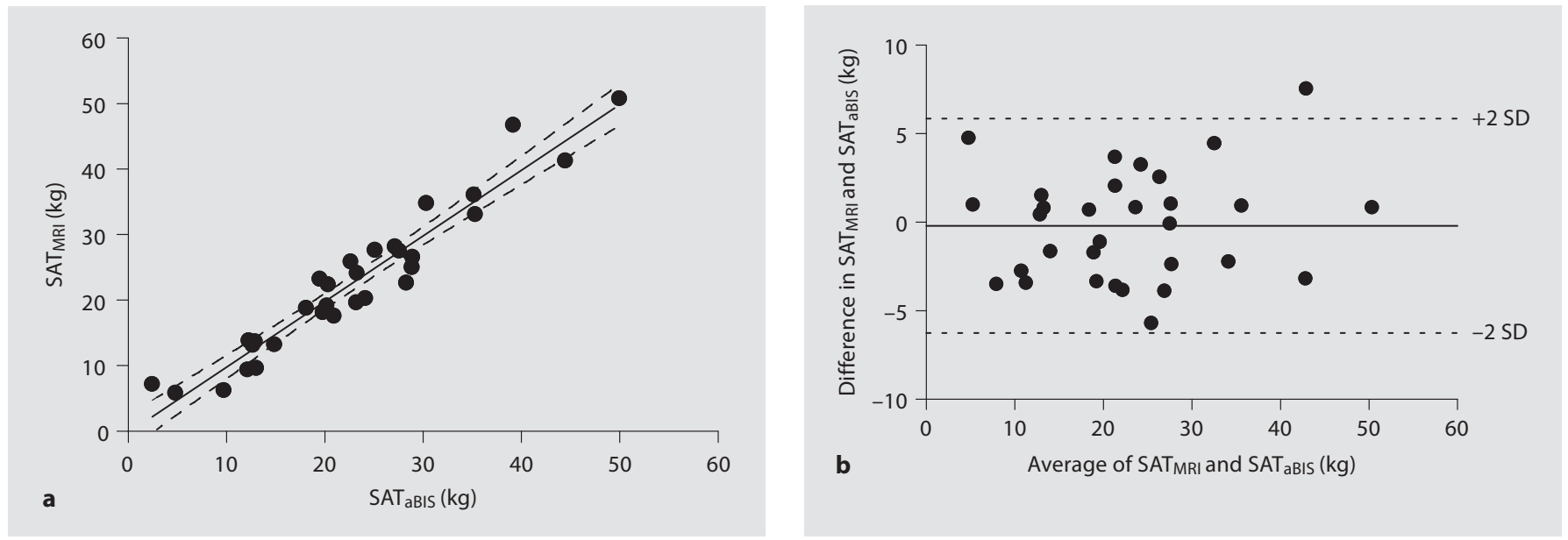

Fig. 2. Correlation $\left(\mathrm{r}^{2}=0.925, \mathrm{SEE}=3.6\right)(\mathbf{a})$ and agreement $(\mathbf{b})$ with Bland-Altman analysis (bias -0.205 with the range from -6.26 to 5.85 ) between gold standard by whole body MRI and estimation by arm BIS model with equation 5 .
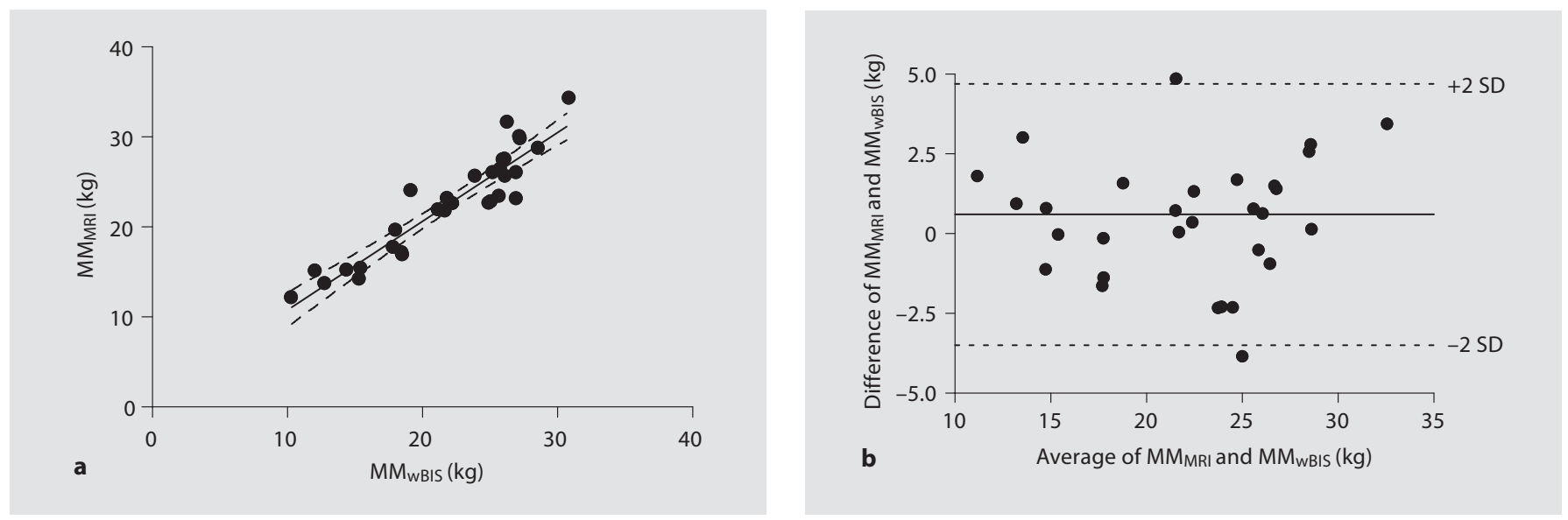

Fig. 3. Correlation $\left(\mathrm{r}^{2}=0.86, \mathrm{SEE}=2.28\right)(\mathbf{a})$ and agreement $(\mathbf{b})$ with Bland-Altman analysis (bias 0.6 with the range from -3.49 to 4.69 ) between gold standard and estimation with equation 6 .

$$
\begin{aligned}
& M M_{M R I}=-0.011 w \mathrm{Re}-0.004 w R i+0.292 H+ \\
& 0.117 B M-0.091 \text { Age }-19.43 .
\end{aligned}
$$

The correlation $\left(\mathrm{r}^{2}=0.86\right.$, SEE $\left.=2.28\right)$ and agreement with Bland-Altman analysis (bias 0.6 with the range from -3.49 to 4.69 ) between gold standard and estimation with equation 6 are shown in figure 3.

$S A T_{M R I}=0.035 \mathrm{Re}+0.005 R i-0.609 H+$
$0.761 B M+0.093 \mathrm{Age}+34.587$.

The correlation $\left(\mathrm{r}^{2}=0.92\right.$, SEE $\left.=3.51\right)$ and agreement with Bland-Altman analysis (bias 0.403 with the range from -5.87 to 6.68 ) between gold standard and estimation with equation 5 are shown in figure 4 .

Body Composition in Dialysis Patients
The correlation (Arm SM $\mathrm{SRI}=0.96 \cdot \mathrm{TAV}_{\mathrm{BIS}}+0.07$, $\mathrm{r}^{2}=0.78$ ) between estimation by $\mathrm{TAV}_{\mathrm{BIS}}$ and Arm SM MRI is shown in figure 5. Corresponding regression lines and $95 \%$ confidence limits (dashed line) are shown in figure 5. Figure 6 shows the correlation between $S_{A T} T_{A r m}$ and Arm SAT ${ }_{\text {BIS }}$ by equation 5 and the regression parameters $\operatorname{Arm~SAT~}_{\mathrm{MRI}}=1.2 \cdot \mathrm{SAT}_{\mathrm{BIS}}+0.5, \mathrm{r}^{2}=0.77, \mathrm{p}<0.0001$. Regression parameters with $\mathrm{TAV}_{\mathrm{BIS}}$ and $\mathrm{PBK}_{\mathrm{Arm}}$ are $\mathrm{PBK}_{\mathrm{Arm}}=2.6 \cdot \mathrm{TAV}_{\mathrm{BIS}}+1.6, \mathrm{r}^{2}=0.62, \mathrm{p}<0.0001$ in figure 7. The correlation between TBK and TAV is shown in figure $8\left(\mathrm{TBK}=1,334 \cdot \mathrm{TAV}+764.2, \mathrm{r}^{2}=0.77\right)$. Figure 9 shows the correlation of TBK to PBK in the arm (TBK = $351.8 \cdot \mathrm{PBK}+919, \mathrm{r}^{2}=0.8$ ). 

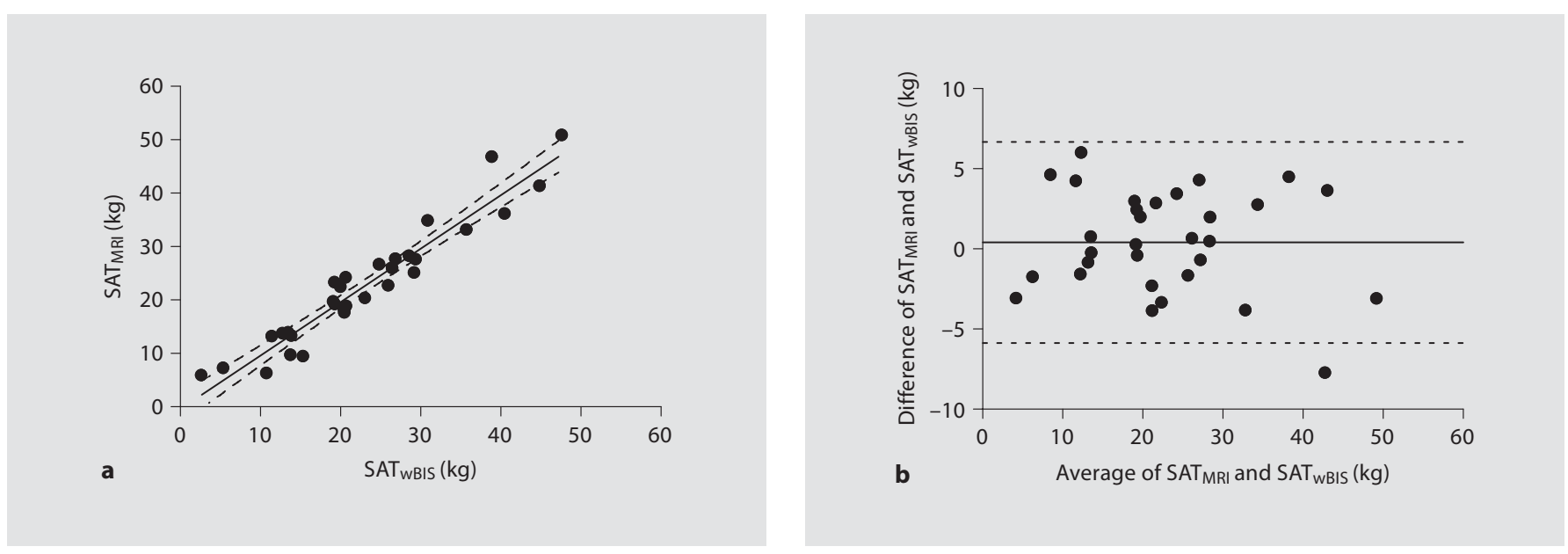

Fig. 4. Correlation $\left(\mathrm{r}^{2}=0.92, \mathrm{SEE}=3.51\right)(\mathbf{a})$ and agreement $(\mathbf{b})$ with Bland-Altman analysis (bias 0.403 with the range from -5.87 to 6.68 ) between gold standard by whole MRI and estimation by arm BIS model with equation 5 .

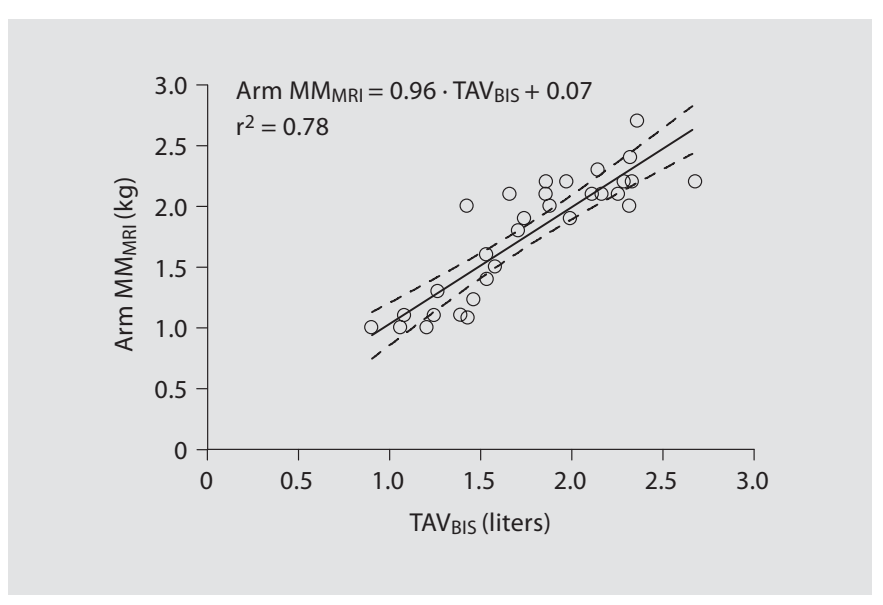

Fig. 5. Correlation $\left(\mathrm{SM}_{\mathrm{MRI}}=0.96 \cdot \mathrm{TAV}_{\mathrm{BIS}}+0.07, \mathrm{r}^{2}=0.78\right)$ between $\mathrm{TAV}_{\mathrm{BIS}}$ and arm MM $\mathrm{MRI}_{\mathrm{M}}$.

\section{Discussion}

This study shows that total body MM and SAT can be estimated using BIS models for the arm and for the whole body when compared to gold standard techniques MRI (fig. 1-4) [25]. Results were similar using the whole body and the arm models, but the arm method was more convenient and might be useful in the future to monitor subjects for evaluating the nutritional status in dialysis patients. In addition, the arm technique could have particular value where the lower limbs are not available for electrode placement.

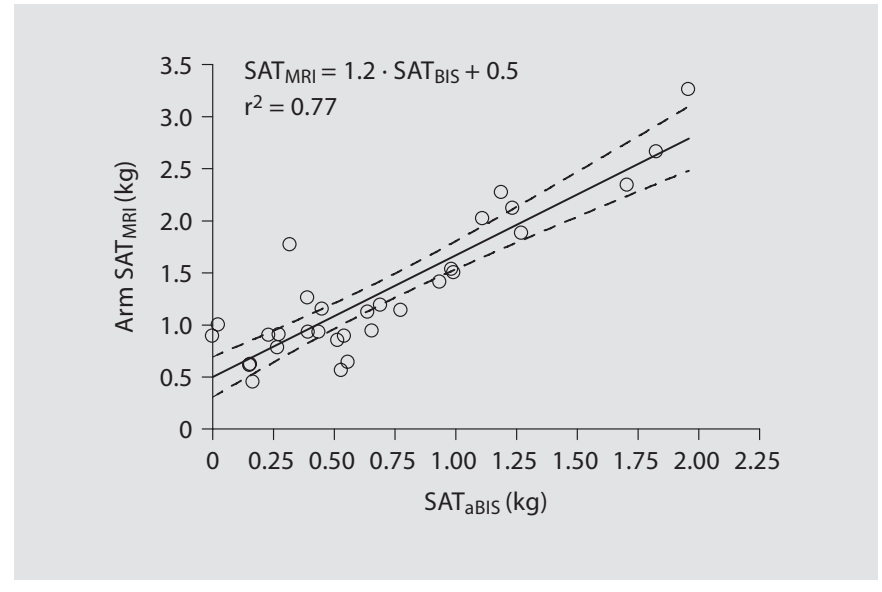

Fig. 6. Correlation $\left(\mathrm{SAT}_{\mathrm{MRI}}=1.2 \cdot \mathrm{SAT}_{\mathrm{BIS}}+0.5, \mathrm{r}^{2}=0.77, \mathrm{p}<\right.$ $0.0001)$ between the arm $S_{A T}$ BIS to the arm $S_{A T}$ MRI.

\section{MRI and SBIS}

Values of total body MM and SAT were similar between by MRI and by the arm BIS models. Although the accuracy of arm BIS models was similar to the whole body model, the arm measurement provides a special technique to monitor body composition for those who need to move their legs such as using a stationary bicycle. The correlation between arm $\mathrm{MM}_{\mathrm{MRI}}\left(\mathrm{r}^{2}=0.78\right)$ or SAT $_{\text {MRI }}\left(r^{2}=0.8\right)$ and $\operatorname{TAV}_{\text {BIS }}(E C V a+I C V a)$ was relatively lower than the correlation between the arm BIS model and total body $\mathrm{MM}_{\mathrm{MRI}}\left(\mathrm{r}^{2}=0.84\right)$ or $\mathrm{SAT}_{\mathrm{MRI}}\left(\mathrm{r}^{2}=\right.$ 0.93 ) (fig. 1, 2, 5, 6). This can be explained by the inaccuracy of arm measurement by MRI because HD patients 


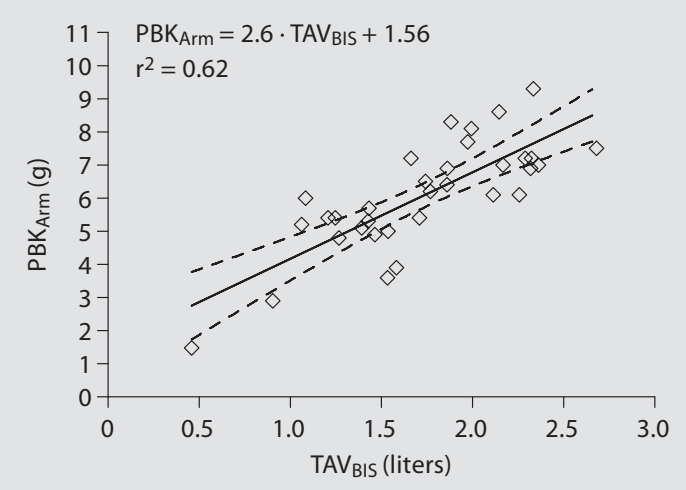

Fig. 7. Correlation $\left(\mathrm{BPK}_{\mathrm{Arm}}=2.6 \cdot \mathrm{TAV}_{\mathrm{BIS}}+1.6, \mathrm{r}^{2}=0.62, \mathrm{p}<\right.$ $0.0001)$ between $\mathrm{PBK}_{\mathrm{Arm}}$ and $\mathrm{TAV}_{\mathrm{BIS}}$.

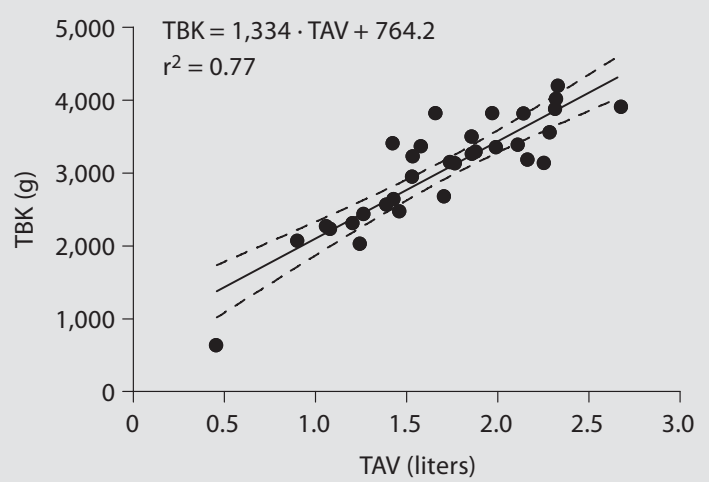

Fig. 8. Correlation between TBK and TAV $(\mathrm{TBK}=1,334 \cdot \mathrm{TAV}+$ 764.2, $\left.\mathrm{r}^{2}=0.77\right)$.

cannot strengthen their arms during the measurement. The accuracy and precision could be affected by the overhydration state of HD patients. In this study, the measurements were taken predialyticly so that the patients were in various degrees of overhydration. Since MM contains body extracellular and intracellular fluid, the accuracy of estimation with MRI is affected because the imaging of cross-sectional areas by MRI cannot separately determine extracellular and intracellular fluid volumes. On the other hand, accuracy of the ICV calculation is also limited by current BIS equations [26].

Body Composition in Dialysis Patients

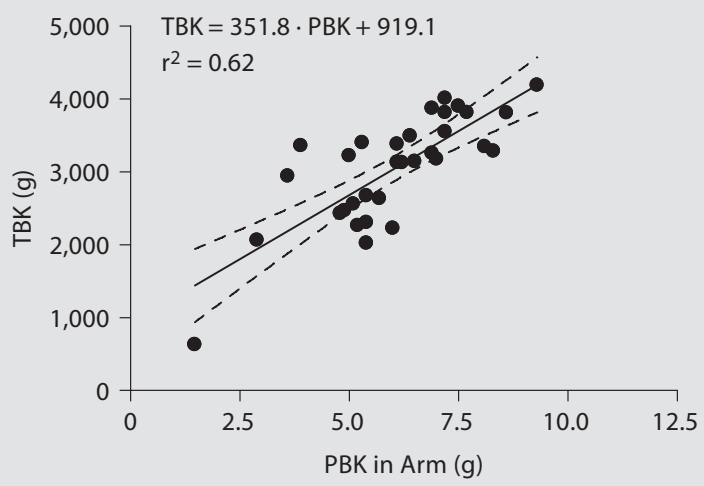

Fig. 9. Correlation of TBK to $\mathrm{PBK}$ in the $\operatorname{arm}(\mathrm{TBK}=351.8 \cdot \mathrm{PBK}$ $\left.+919, \mathrm{r}^{2}=0.62\right)$

\section{${ }^{40} \mathrm{~K}$ and SBIS}

${ }^{40} \mathrm{~K}$ provides information of body cell mass in arm segments and in the total body which relates to energy production and creatinine generation [27]. Decrease in TBK has been associated with a significantly increased mortality of dialysis patients [28]. The correlation between $\mathrm{TAV}_{\text {BIS }}$ and TBK was $\mathrm{r}^{2}=0.77$, so that it is possible to use the value of $\mathrm{TAV}_{\mathrm{BIS}}$ to predict total body cell mass with the arm SBIS method within an acceptable margin of errors. Although the value of $\mathrm{PBK}_{\mathrm{Arm}}$ representing cell mass in the arm could be helpful in the calibration of ICV in the arm with BIS, the correlation (fig. 5) between $\mathrm{PBK}_{\mathrm{Arm}}$ and $\mathrm{TAV}_{\mathrm{BIS}}\left(\mathrm{PBK}_{\mathrm{Arm}}=2.6 \cdot \mathrm{TAV}_{\mathrm{BIS}}+1.6, \mathrm{r}^{2}=\right.$ 0.62 ) must be improved in order to obtain adequate precision for clinical use. The current somewhat poor results can be explained by differences in the length of arm inserted into the ${ }^{40} \mathrm{~K}$ counter and that used for the arm BIS and $\mathrm{PBK}_{\mathrm{Arm}}$. Accuracy can be improved in the future by calibration of the arm length using an affixed marker when performing the measurements.

Although whole body and sum of segmental bioimpedance provide considerable accuracy for total body composition estimation, the techniques require subjects to be kept in a supine body position and this may not be convenient for monitoring the patient in dialysis. From a technical point of view, the quality of bioimpedance signals could be improved by using the arm method because the length of electrode cables can be reduced. In addition, there is considerable body fluid shift from the leg to trunk with a change in the body position from standing to supine during measurement with the whole body bioimpedance method 
[29]. This redistribution of fluid volume from limbs to trunk can produce a substantial variability in bioimpedance data and significantly reduce the precision of whole body measurements [30]. However, with the arm method there is no change in the fluid volume during the measurement so that the precision and accuracy can be fundamentally improved. The usefulness of arm BIS depends on its clinical application, e.g. to evaluate change in MM after nutritional or other interventions. It is an advantage if the arm SBIS can be used to monitor changes in body composition status simply, quickly and reproducibly.

\section{Conclusions}

The arm segmental bioimpedance approach provides an inexpensive and noninvasive technique for the evaluation of body composition and nutritional status in di- alysis patients. The results indicate that the total body MM and SAT can be estimated using the measurement of bioimpedance in the arm. This method could have application in assessing nutritional status in HD patients. Measurement of MM with the calculation of creatinine generation could improve the formulae for the calculation of GFR using serum creatinine. The arm method may have particular advantage over the whole body technique in some applications.

\section{Acknowledgments}

The authors express their thanks to the colleagues who assisted in the study at the Yorkville Dialysis Center, RRI.

\section{References}

1 Kalantar-Zadeh K, Abbott KC, Salahudeen AK, Kilpatrick RD, Horwich TB: Survival advantages of obesity in dialysis patients. Am J Clin Nutr 2005;81:543-554.

$\checkmark 2$ de Vries PM, Folkers HB, de Fijter CW, van der Meulen J, Luitingh-van der Veen $M$, Popp-Snijders C, Oe LP: Adipose tissue fatty acid composition and its relations to diet and plasma lipid concentrations in hemodialysis patients. Am J Clin Nutr 1991;53:469-473.

>3 Johansen KL, Kaysen GA, Young BS, Hung AM, da Silva M, Chertow GM: Longitudinal study of nutritional status, body composition, and physical function in hemodialysis patients. Am J Clin Nutr 2003;77:842-846.

$\checkmark 4$ Combe C, Chauveau P, Laville M, Fouque D, Azar R, Cano N, Canaud B, Roth H, Leverve $\mathrm{X}$, Aparicio M: Influence of nutritional factors and hemodialysis adequacy on the survival of 1,610 French patients. Am J Kidney Dis 2001;37:S81-S88.

$\checkmark 5$ Kotanko P, Thijssen S, Levin NW: Association between erythropoietin responsiveness and body composition in dialysis patients. Blood Purif 2008;26:82-89.

6 Castaneda-Sceppa C, Sarnak MJ, Wang X, Greene T, Madero M, Kusek JW, Beck G, Kopple JD, Levey AS, Menon V: Role of adipose tissue in determining muscle mass in patients with chronic kidney disease. J Ren Nutr 2007; 17:314-322.
7 Johansen KL, Painter PL, Sakkas GK, Gordon P, Doyle J, Shubert T: Effects of resistance exercise training and nandrolone decanoate on body composition and muscle function among patients who receive hemodialysis: a randomized, controlled trial. J Am Soc Nephrol 2006;17:2307-2314.

$\checkmark 8$ Axelsson J: Obesity in chronic kidney disease: good or bad? Blood Purif 2008;26:2329.

9 Pierson RN Jr, Wang J, Thornton JC: Body composition comes of age: a modest proposal for the next generation: the new reference man. Ann NY Acad Sci 2000;904:1-11.

10 Woodrow G, Oldroyd B, Wright A, Coward WA, Turney JH, Brownjohn AM, Truscott JG, Smith MA: The measurement of total body potassium in patients on peritoneal dialysis. Perit Dial Int 2001;21(suppl 3):S163S167.

11 Wielopolski L, Ramirez LM, Gallagher D, Sarkar SR, Zhu F, Kaysen GA, Levin NW, Heymsfield SB, Wang ZM: Measuring partial body potassium in the arm versus total body potassium. J Appl Physiol 2006;101: 945-949.

12 Chertow GM, Lowrie EG, Wilmore DW, et al: Nutritional assessment with bioelectrical impedance analysis in maintenance hemodialysis patients. J Am Soc Nephrol 1995;6: 75-81.
13 Kaysen GA, Zhu F, Sarkar S, Heymsfield SB, Wong J, Kaitwatcharachai C, Kuhlmann MK, Levin NW: Estimation of total-body and limb muscle mass in hemodialysis patients by using multifrequency bioimpedance spectroscopy. Am J Clin Nutr 2005;82: 988-995

14 Kuhlmann MK, Levin NW: How common is malnutrition in ESRD? New approaches to diagnosis of malnutrition. Blood Purif 2008; 26:49-53.

15 Kusztal M, Kleszczynski J, Weyde W, Makulska I, Porazko T, Golebiowski T, Krajewska M, Zwolinska D, Klinger M: Pulse volume changes recorded by air plethysmography during single hemodialysis sessions. Blood Purif 2008;26:498-504.

16 Levin NW, Zhu F, Keen M: Interdialytic weight gain and dry weight. Blood Purif 2001;19:217-221.

17 Organ LW, Bradham GB, Gore DT, Lozier SL: Segmental bioelectrical impedance analysis: theory and application of a new technique. J Appl Physiol 1994;77:98-112.

$>18$ Zhu F, Schneditz D, Kaufman AM, Levin NW: Estimation of body fluid changes during peritoneal dialysis by segmental bioimpedance analysis. Kidney Int 2000;57: 299-306

19 Zhu F, Kuhlmann MK, Kaysen GA, Sarkar S, Kaitwatcharachai C, Khilnani R, Stevens L, Leonard EF, Wang J, Heymsfield S, Levin NW: Segment-specific resistivity improves body fluid volume estimates from bioimpedance spectroscopy in hemodialysis patients. J Appl Physiol 2006;100:717-724. 
-20 Tanaka NI, Miyatani M, Masuo Y, Fukunaga T, Kanehisa H: Applicability of a segmental bioelectrical impedance analysis for predicting the whole body skeletal muscle volume. J Appl Physiol 2007;103:1688-1695.

-21 Stahn A, Terblanche E, Strobel G: Modeling upper and lower limb muscle volume by bioelectrical impedance analysis. J Appl Physiol 2007;103:1428-1435.

-22 Sarkar SR, Kuhlmann MK, Khilnani R, Zhu F, Heymsfield SB, Kaysen GA, Levin NW: Assessment of body composition in longterm hemodialysis patients: rationale and methodology. J Ren Nutr 2005;15:152-158.

-23 Ross R, Leger L, Morris D, de Guise J, Guardo R: Quantification of adipose tissue by MRI: relationship with anthropometric variables. J Appl Physiol 1992;72:787-795.
24 De Lorenzo A, Andreoli A, Matthie J, Withers P: Predicting body cell mass with bioimpedance by using theoretical methods: a technological review. J Appl Physiol 1997;82: 1542-1558.

25 Janssen I, Heymsfield SB, Baumgartner RN, Ross R: Estimation of skeletal muscle mass by bioelectrical impedance analysis. J Appl Physiol 2000;89:465-471.

26 Moissl UM, Wabel P, Chamney PW, Bosaeus I, Levin NW, Bosy-Westphal A, Korth O, Muller MJ, Ellegard L, Malmros V, Kaitwatcharachai C, Kuhlmann MK, Zhu F, Fuller NJ: Body fluid volume determination via body composition spectroscopy in health and disease. Physiol Meas 2006;27:921-933.
27 Burmeister W: Potassium-40 content as a basis for the calculation of body cell mass in man. Science 1965;148:1336-1337.

28 Letteri JM, Ellis KJ, Asad SN, Cohn SH: Serial measurement of total body potassium in chronic renal disease. Am J Clin Nutr 1978; 31:1937-1944.

29 Zhu F, Schneditz D, Wang E, Levin NW: Dynamics of segmental extracellular volumes during changes in body position by bioimpedance analysis. J Appl Physiol 1998;85: 497-504.

30 Scharfetter H, Monif M, Laszlo Z, Lambauer T, Hutten H, Hinghofer-Szalkay H: Effect of postural changes on the reliability of volume estimations from bioimpedance spectroscopy data. Kidney Int 1997;51:1078-1087. 